\title{
Laboratory Profile of HIV-2 and Dual HIV-1/HIV-2 Associated Acquired Immunodeficiency Syndrome in Nigeria*
}

\author{
Georgina Njideka Odaibo ${ }^{\#}$, David Olufemi Olaleye \\ Department of Virology, College of Medicine, University of Ibadan, University College Hospital, Ibadan, Nigeria. \\ Email: \#davidoolaleye@gmail.com
}

Received June $21^{\text {st }}$, 2013; revised July 21 ${ }^{\text {st }}$, 2013; accepted July $30^{\text {th }}, 2013$

Copyright (C) 2013 Georgina Njideka Odaibo, David Olufemi Olaleye. This is an open access article distributed under the Creative Commons Attribution License, which permits unrestricted use, distribution, and reproduction in any medium, provided the original work is properly cited.

\begin{abstract}
Background: HIV-2 is comparatively less pathogenic with slow progression of infection to clinical disease and consequently there is less of information on the occurrence of HIV-2 associated disease than HIV-1. We hereby describe some laboratory profiles of individuals presenting with HIV-2 and dual HIV-1/2 related AIDS at the University College hospital in Ibadan over a period of seven years. Methodology: Blood samples from patients presenting with the AIDS defining illness at the University College Hospital, Ibadan, Nigeria were tested for antibodies to HIV-1/2 using rapid test devices or ELISA. Initially reactive samples were further tested by immunoblotting for differentiation into HIV-1 or HIV-2 or HIV-1/2 dual infection. Blood samples from individuals with confirmed infections were further analyzed for CD4 cell lymphocyte number, plasma HIV-1 RNA concentration, hematological and blood chemistry parameters. The data analysis was done using descriptive statistics and Levene-S test for equality of variance. Results: Thirty five patients, 18 and 17 with HIV-2 and dual HIV-1/2 infections respectively were identified during the period covered by this study (2005-2012). The median age of the patients was 48 years old (Range: 42 - 70 years old) and mean CD4 cell count of HIV-2 patients at enrollment was 324 (Range: 16 - 696) and 350 (Range 54 - 863) per microlitre of blood for patients with dual HIV-1/2 infection. HIV-1 RNA was not detected in the plasma of the 18 patients with serological HIV-2 infection but 2 (11.8\%) of the 17 patients with dual HIV-1/2 serological profile had detectable HIV-1 RNA $(1,287,275$ copies/ml and 1,816,491 copies/ml). Conclusion: The results emphasize the need to consider HIV-2 infection in the investigation of patients presenting with the AIDS related illness but with negative HIV-1serology. The study also shows the importance of inclusion of multispot HIV-1 and 2 rapid tests for differentiating HIV-1 from HIV-2 infections in regions where both types of HIV circulate or epidemiologically indicated.
\end{abstract}

Keywords: HIV-2; HIV1/2 Dual Infection; CD4; Hematology; Chemistry; Nigeria

\section{Introduction}

One of the major complications and perhaps the most interesting feature of the biology of the Human Immunodeficiency Virus (HIV) is the tremendous genetic diversity of the virus. The high degree of diversity of HIV has important implications for host susceptibility, transmission,

\footnotetext{
${ }^{*}$ Competing interest: We declare that we have no conflicting interest in the conduct of the study.

Authors' contribution: GNO and DOO conceived the idea of the study, GNO, DOO were involved in collection and analysis of data, GNO supervised the laboratory investigations. GNO wrote the draft manuscript while both authors reviewed the final manuscript and approved the final version. DOO is the guarantor of the paper.

${ }^{\#}$ Corresponding author.
}

pathogenesis, the diagnosis, susceptibility to antiretroviral drugs and the design of vaccine against the virus among others [1-3]. Presently, two types of the virus are known to infect and cause disease in human, HIV-1 and HIV-2. The HIV epidemic is characterized by the presence of both types in West Africa, including Nigeria where HIV1 and HIV-2 infections have been reported at varying proportions in different population groups over time [46]. While HIV-1 has a higher propensity for variability with subsequent evolution of several subtypes and circulating recombinant forms [2,3], HIV-2 has been relatively stable with lower rate of transmission, less pathogenic, infection progression of infection to clinical disease and limited occurrence of HIV-2 associated disease [2,3,7-9]. 
In Nigeria, the rate of occurrence of the two types of HIV was about the same at the beginning of the epidemic [2, 4-6], but the relative rate of HIV-2 infection declined over the years to less than $0.5 \%$ among infected persons in different parts of the country [10]. Consequently, attention has not been placed on the differential diagnosis of HIV-1 and HIV-2 and little or no preparation for the management of HIV-2 related disease in West Africa where circulation of the virus is predominant [11].

Scaling up of HIV prevention, treatment and care programmes started in 2002 in Nigeria with tremendous success to date. The University College hospital in Ibadan is one of the reference centres in southwestern Nigeria where laboratory facilities are available for the differential diagnosis of HIV-1 and HIV-2 infections, treatment and monitoring, in addition to cytometry, HIV-1 RNA (viral load assay) and drug resistance testing. In this publication, we describe the occurrence and some laboratory profiles of individuals presenting with HIV-2 and dual HIV-1/2 related Acquired Immunodeficiency Syndromes (AIDS) at the University College hospital in Ibadan over a period of seven years.

\section{Materials and Methods}

\subsection{Study Population and Samples}

The study population consisted of three categories of individuals; persons presenting for VCT, pregnant women participating in the PMCTC and patients referred for HIV diagnoses from clinics and wards from within and outside the University College hospital, Ibadan. Individuals included were aged 18 years or older and were provided with appropriate counseling for HIV testing. Those who consented were tested for HIV-1 and HIV-2 infections, informed of their serological status and referred for appropriate care and management based on the protocol in the Federal Ministry of Health of Nigeria approved HCT and HIV treatment guidelines. The present study included results of HIV tests that were carried out from January 2005 to December 2011.

\subsection{Laboratory Methods}

Combination HIV-1/HIV-2 screening tests using the algorithm recommended by the Federal Ministry of Health of Nigeria were used for this study. Initial combination test for HIV-1/HIV-2 was performed and for any reactive specimen, more specific testing to confirm the presence of antibodies either to HIV-1 or HIV-2 was performed. Rapid HIV screening procedures were performed at the referring laboratories according to a serial testing algorithm with two distinct rapid HIV assays, the Determine HIV-1/2 assay (Determine assay; Abbott Laboratories, Abbott Park, Ill.) and STAT PAK HIV-1/HIV-2 assay. A specimen was considered reactive if it tested positive for
HIV antibodies in a combination HIV-1/HIV-2 EIA or rapid test device. Both tests are rapid test devices that are based on the specific detection of anti-HIV-1 and antiHIV-2 antibodies by antigens that bind to the different antibody binding sites. The results are also interpreted visually as reactive or non-reactive.

Reactive specimens were further tested first, by Western blot technique that detects and differentiate antibodies to HIV-1 or HIV-2. In some cases, specimens that were reactive by the combination HIV-1/HIV-2 test were first tested by Western blot for HIV-1 only and those negative or indeterminate for HIV-1 antibodies were tested again using HIV-2 Western blot assay (LAV Blot 2). In both strategies, interpretation of the assays was based on the recommendation of the manufacturers of the commercial kits used.

All serological assays for differentiation between HIV1 and HIV-2 were carried out in the Department of Virology, University College hospital, Ibadan, Nigeria.

\subsection{Laboratory Parameters and Analysis}

Relevant demographic, clinical and blood specimens for laboratory parameters on the patients were collected at the time of enrolment and follow up visits. HIV related disease staging at the time of enrolment was determined using the CDC classification criteria. Laboratory profile assessed included absolute CD4 cell count and HIV-1 plasma RNA, full blood count as well as blood urea, creatinine, ALT and glucose levels. Data were analyzed using descriptive statistics and Levene-S test for equality of variance.

\section{Results}

A total of 35 patient presenting with AIDS related illness including 18HIV-2 and 17 dual HIV1/2 infection were enrolled over a period of 7 years (2005-2012) covered by this study. They included $14 \mathrm{M}, 4 \mathrm{~F}$ for HIV-2 and $4 \mathrm{M}$, 13F for HIV-2 and dual HIV-2 respectively. The median age of the patients at enrolment was 48 years (Range: 42 - 70 years). The mean CD4 cell count of HIV-2 patients at enrolment was 324 (Range: 16 - 696) and 350 (range 54 - 863) per microlitre of blood for patients with dual HIV-1/2 infection (Table 1). The mean CD4 cell count of HIV-2 infected male patients was higher than that of the female but the reverse is the situation between mean CD4 cell count of the male and female patients infected with dual HIV-1/2 infection (Table 2). The other parameters were within the range of normal values. There was no significant difference between the HIV-2 and HIV$1 / 2$ dually infected patients. Similarly, there was no significant difference in the value of the parameters between male and female patients in the two groups except in the white blood cell counts that was significantly higher $(\mathrm{P}=$ 0.02) among female than male patients dually infected 
with HIV-1/2 (Table 2).

The levelof blood urea among patients infected with HIV-1/2 was significantly higher in those infected with HIV-2 alone. In addition, the level of creatinine was higher than the normal value for the population in the study area. HIV-1 RNA was not detected in the plasma of the 18 patients with serological HIV-2 infection. On the other hand, two $(11.8 \%)$ of the 17 patients with dual HIV-1/2 serological profile had detectable HIV-1 RNA $(1,287,275$ copies/ml and 1,816,491 copies/ml) at presentation. The value of each of the other blood parameters analyzed in the samples of the patients is also shown in Tables 1 and 2.

\section{Discussion}

The relative low rate of HIV-2 and HIV-1/2 infection compared to HIV-1 among patients that presented for treatment in our facility in southwestern Nigeria over a period of seven years covered by this study is in agreement with previous reports on the declining rate of HIV2 and dual HIV-1/2 in the country since 1985 [2]. However, it is significant to note that these individuals are presented with AIDS defining clinical conditions which emphasize the need to consider HIV-2 infection in patients with the clinical definition of AIDS but negative HIV-1. These cases of HIV-2 related AIDS in our series

Table 1. Value of some laboratory parameters of persons presenting with HIV-2 and HIV-1/2 associated AIDS in Nigeria.

\begin{tabular}{|c|c|c|c|c|c|}
\hline \multirow{2}{*}{$\mathrm{S} / \mathrm{N}$} & \multirow{2}{*}{ Parameter } & \multirow{2}{*}{ Normal range (Nigeria) } & HIV-2 (N = 18) & HIV $1 / 2(\mathrm{~N}=17)$ & \multirow{2}{*}{ P-value } \\
\hline & & & Mean $( \pm S D)$ & Mean $( \pm S D)$ & \\
\hline 1 & CD4 & 365 - 1571 cells/ul & 323.9 (213.6) & 350.1 (251.5) & 0.74 \\
\hline 2 & Urea & $15-45 \mathrm{Mg} / \mathrm{dL}$ & $19.0(7.5)$ & $36.3(35.3)$ & 0.05 \\
\hline 3 & WBC & $4500-10,000 \mu \mathrm{L}$ & 4227.8 (1545.3) & 3788.6 (1320.3) & 0.34 \\
\hline 4 & ALT & 12 - $40 \mathrm{IU} / \mathrm{L}$ & $26.4(22.6)$ & $20.5(11.7)$ & 0.54 \\
\hline 5 & Creatinine & $0.1-0.4 \mathrm{Mg} / \mathrm{dL}$ & $0.9(0.3)$ & $1.1(1.7)$ & 0.99 \\
\hline 6 & Glucose & $60-120 \mathrm{Mg} / \mathrm{dL}$ & $89.6(12.4)$ & $88.1(11.7)$ & 0.40 \\
\hline 7 & Hemoglobin & $10-14 \mathrm{~g} / \mathrm{dL}$ & $10.4(2.5)$ & $10.4(2.3)$ & 0.72 \\
\hline
\end{tabular}

Table 2. Comparison by gender of some laboratory parameters of persons presenting with HIV-2 and HIV-1/2 associated AIDS in Nigeria.

\begin{tabular}{|c|c|c|c|c|c|c|}
\hline \multirow{2}{*}{$\mathrm{S} / \mathrm{N}$} & \multirow{2}{*}{ Parameter } & \multirow{2}{*}{ Normal range (Nigeria) } & \multicolumn{2}{|c|}{ HIV-2 $(\mathrm{N}=18)$ Male $=14$, Female $=4$} & \multicolumn{2}{|c|}{ HIV $1 / 2(\mathrm{~N}=17)$ Male $=4$, Female $=13$} \\
\hline & & & Mean $( \pm S D)$ & P-value & Mean $( \pm$ SD) & P-value \\
\hline \multirow[t]{2}{*}{1} & CD4 male & 351 - 1455 cells/ul & $364.4(219.0)$ & \multirow{2}{*}{0.14} & $145.5(47.6)$ & \multirow{2}{*}{0.06} \\
\hline & Female & 385 - 1654 cells/ul & $182.3(128.3)$ & & $413.0(256.0)$ & \\
\hline \multirow[t]{2}{*}{2} & Urea male & \multirow{2}{*}{$15-45 \mathrm{Mg} / \mathrm{dL}$} & $19.4(8.0)$ & \multirow{2}{*}{0.72} & $43.0(51.8)$ & \multirow{2}{*}{0.68} \\
\hline & Female & & $17.8(6.0)$ & & $34.2(31.2)$ & \\
\hline \multirow[t]{2}{*}{3} & WBC male & \multirow{2}{*}{$4500-10,000 \mu \mathrm{L}$} & $4000.0(1547.2)$ & \multirow{2}{*}{0.25} & $2476.5(1653.0)$ & \multirow{2}{*}{0.02} \\
\hline & Female & & $5025.0(1438.5)$ & & $4192.3(943.8)$ & \\
\hline \multirow[t]{2}{*}{4} & ALT male & \multirow{2}{*}{12 - $40 \mathrm{IU} / \mathrm{L}$} & $29.1(25.1)$ & \multirow{2}{*}{0.35} & $21.5(6.6)$ & \multirow{2}{*}{0.85} \\
\hline & Female & & $16.8(4.9)$ & & $20.2(13.1)$ & \\
\hline \multirow[t]{2}{*}{5} & Creatinine male & \multirow[b]{2}{*}{$0.1-0.4 \mathrm{Mg} / \mathrm{dL}$} & $0.9(0.3)$ & \multirow[b]{2}{*}{0.59} & $0.7(0.2)$ & \multirow[b]{2}{*}{0.59} \\
\hline & Female & & $0.8(0.3)$ & & $1.2(1.9)$ & \\
\hline \multirow[t]{2}{*}{6} & Glucose male & \multirow{2}{*}{$60-120 \mathrm{Mg} / \mathrm{dL}$} & $88.5(13.2)$ & \multirow{2}{*}{0.49} & $87.5(9.6)$ & \multirow{2}{*}{0.91} \\
\hline & Female & & $93.5(9.4)$ & & $88.3(12.6)$ & \\
\hline \multirow[t]{2}{*}{7} & Hemoglobin male & \multirow{2}{*}{$10-14 \mathrm{~g} / \mathrm{dL}$} & 10.5 (1.9) & \multirow[b]{2}{*}{0.90} & $9.6(1.4)$ & \multirow[b]{2}{*}{0.40} \\
\hline & Female & & $10.3(4.6)$ & & $10.7(2.4)$ & \\
\hline
\end{tabular}


call for urgent inclusion of multispot HIV-1 and 2 rapid test for differentiating HIV-1 from HIV-2 infections in settings where both types of HIV circulate or epidemiologically indicated. This approach will help to resolve cases of HIV-2 associated AIDS in many African countries where the alternative strategy of the HIV diagnosis of parallel or serial rapid test device is used due to the high cost of immuno-blotting assays [11].

It is also worthy to note that the age ranges of the patients with HIV-2 and dual HIV-1/2 infections are different from that of HIV-1 infected persons in Nigeria [4-6, 10] and many other African countries [12-14]. While the highest rate of HIV-1 infected persons remains the 19 24 years old in Nigeria, the age range of 40 - 72 years old of persons infected with HIV-2 and dual HIV-1/2 in the cohort reported in this paper lends credence to low transmissibility of HIV-2 [14]. The data suggest that the individuals with HIV-2 related AIDS clinical conditions who presented in our facility may have been infected several years before progression to AIDS [4-6,15]. Previous reports from the same region of the country showed that rates of HIV-1 and HIV-2 infections were about the same during the late 1980s and early 1990s [4-6] before a progressive decline in the relative rate of HIV-2 to HIV-1 infections to the current situation of less than $1 \%$ of HIV2 infection rate in the country [10].

The low mean CD4 cell count of the patients shows that though infection may take a longer period, HIV-2 causes AIDS in infected persons thus the need for appropriate therapy cannot be overemphasized. The mean CD4 cell count of 324 (Range: 16 - 769) and 350 (Range: 54 863) of HIV-2 and HIV-1/2 infected patients respectively in the cohort reported in this paper is lower than the reported mean of CD4 cell count of healthy Nigerians [16]. Four (22.2\%) out of the 18 patients with HIV-2 and 5 (29.4\%) of the 17 patients with HIV-1 and 2 presented with CD4 cell count less than 200/ul of blood. Based on the current national guidelines for treatment of HIV/ AIDS in Nigeria [17] 20 (57.1\%) out of the 35 patients described in this report presented with CD4 cell counts below 350/ul of blood. This finding also indicates an urgent need for inclusion of the protocol for a correct diagnosis and treatment of HIV-2 infected persons in the treatment guidelines in West African countries and other places where management of HIV-2 infection may be epidemiologically indicated. It is also important that reference HIV laboratories are strengthened to carry out the qualitative HIV-2 RNA assay for appropriate monitoring of patients on antiretroviral therapy for HIV-2. Detection of a high titre of plasma HIV-1 RNA in two of the 17 patients with dual HIV-2 and HIV-1 and 2 serological profiles is significant. There have been reports of the occurrence of dual HIV-1 and HIV-2 infections in the same individual $[11,18]$ with suggestions of possibilities that recombination events of HIV-1 and HIV-2 will occur [18] and also the new variants of HIV [2,18]. The two patients with detectable and high plasma HIV-1 RNA in this cohort also had very low CD4 cell counts (97 and 54/ul respectively). This situation suggests previous HIV-2 infection that was superimposed with HIV-1 infection in the acute phase just before presentation for AIDS related care. As far as we can establish, this is the first description of HIV-2 associated AIDS from Nigeria.

\section{What Is Already Known on This Subject}

Previous reports have shown endemic presence and circulation of HIV-2 in West Africa, including Nigeria. Studies have also shown a low rate of transmission of HIV-2 and slow progression to clinical disease relative to HIV-1.

\section{What This Study Adds to Literature}

The results of this study describe laboratory parameters in patients presenting with HIV-2 and dual HIV-1/HIV-2 infection in settings where both HIV-1 and HIV-2 co-circulate. Results of the study will raise the index of suspicion among health care providers to consider HIV-2 as a differential diagnosis in patients presenting with the AIDS defining illness but with negative HIV-1 serology. The study has also provided the much needed reference laboratory data for proper management of HIV-2 associated AIDS in HIV-2 endemic areas and other epidemiologically significant locations or situations.

\section{Acknowledgements}

The ART program at the University College Hospital is supported by USG PEPFAR program through a Cooperative Agreement (No: 1U2GPS001058) from the Centers for Disease Control and Prevention. The content of this article is solely the responsibility of the authors and does not necessarily represent the official views of the Centers for Disease Control and Prevention. We are grateful to all the staffs of the ART clinic and Virology laboratory for the patient enrollment and laboratory analysis. We also appreciate our patients who participated in the study.

\section{Ethical Considerations}

Approval for the study was obtained from the University of Ibadan/University College hospital ethical review board. Informed consent was obtained from all participants in the study.

\section{REFERENCES}

[1] P. J. Kanki, "Biologic Features of HIV-2: An Update,” AIDS Clinical Review, 1991, pp. 17-38.

[2] D. O. Olaleye, T. O. Harry and G. N. Odaibo, "The Virology and Dynamics of the Epidemic,” In: O. Adeyi, P. J. Kanki, O. Odutolu and J. A. Idoko, Eds., AIDS in Nigeria: A Nation on the Threshold, Harvard Center for Population and Development, Cambridge, 2006, pp. 37-66. 
[3] S. T. Meloni, A. Ojesina and D. O. Olaleye, “The Molecular Epidemiology of HIV,” In: O. Adeyi, P. J. Kanki, O. Odutolu and J. A. Idoko, Eds., AIDS in Nigeria: A Nation on the Threshold, Harvard Center for Population and Development, Cambridge, 2006, pp. 67-92.

[4] D. Olaleye, L. Bernstein, C. Ekwezor et al., "Prevalence of Human Immunodeficiency Virus Type 1 and 2 Infections in Nigeria,” The Journal of Infectious Diseases, Vol. 167, No. 3, 1993, pp. 710-714. doi:10.1093/infdis/167.3.710

[5] J. Chikwen, I. Mohammed and O. T. Oyebode, "Prevalence of Human Immunodeficiency Virus (HIV) Infection in Borno State of Nigeria,” East African Medical Journal, Vol. 65, No. 5, 1988, pp. 342-346.

[6] T. Harry, O. Ekanna, J. Chikwen et al., "Seroepidemiology of Human Immunodeficiency Virus Infection in Borno State of Nigeria by Sentinel Sueveillance,” Journal of Acquired Immune Deficiency Syndrome, Vol. 6, No. 1, 1993, pp. 99-103.

[7] S Jaffar, A. D. Grant, J. Whitworth, P. G. Smith and H. Whittle, "The Natural History of HIV-1 and HIV-2 Infections in Adults in Africa: A Literature Review," Bulletin of World Health Organization, Vol. 82, No. 6, 2004, pp. 462-469.

[8] A. G. Poulsen, P. Aaby, O. Larsen et al., "9-Year HIV-2 Associated Mortality in an Urban Community in Bissau," West African Lancet, Vol. 349, No. 9056, 1997, pp. 911914. doi:10.1016/S0140-6736(96)04402-9

[9] H. Whittle, J. Morris and J. Todd, T. Corrah, S. Sabally, J. Bangali, P. T. Ngom, M. Rolfe and A. Wilkins, "HIV-2 Infected Patients Survive Longer than HIV-1-Infected Patients,” AIDS, Vol. 8, No. 11, 1994, pp. 1617-1620. doi:10.1097/00002030-199411000-00015

[10] Fedral Ministry of Health, "Nigeria; National HIV SeroPrevalence Sentinel Survey among Pregnant Women Attending Antenatal Clinics in Nigeria,” Technical Report, 2010, pp. 1-96.
[11] K. Peterson, S. Jallow, S. L. Rowland-Jones and T. I. de Siliva, “Antiretroviral Therapy for HIV-2 Infection: Recommendations for Management in Low-Resource Settings,” AIDS Research and Treatment, 2011, p. 13.

[12] A. S. Alabi, S. Jaffar, Ariyoshi et al., "Plasma Viral Load, CD4 Cell Percentage, HLA and Survival of HIV-1, HIV2 and Dually Infected Gambian Patients,” AIDS, Vol. 17, No. 10, 2003, pp. 1513-1520.

[13] S. Jallow, A. Alabi, R. Sarge-Njie et al., "Virological Response to Highly Active Antiretroviral Therapy in Patients Infected with Human Immunodeficiency Virus Type 2 (HIV-2) and Patients Dually Infected with HIV-1 and HIV-2 in the Gambia and Emergence of Drug-Resistant Variants,” Journal of Clinical Microbiology, Vol. 47, No. 7, 2009, pp. 2200-2208. doi:10.1128/JCM.01654-08

[14] P. J. Bock and D. M. Markovitz, "Infection with HIV-2," AIDS, Vol. 15, 2001, pp. S35-S45. doi:10.1097/00002030-200100005-00006

[15] N. K. Barry, S. Ariyoshi, S. Jaffar et al., "Low Peripheral Blood Viral HIV-2 RNA in Individuals with High CD4 Percentage Differentiates HIV-2 from HIV-1 Infection," Journal of Human Virology, Vol. 1, 1998, pp. 457-468.

[16] D. K. Oladepo, E. O. Idigbe, R. O. Audu et al., "Establishment of Reference CD4 and CD8 Lymphocyte Subsets in Healthy Nigerian Adults,” Clinical and Vaccine Immunology, Vol. 16, No. 9, 2009, pp. 1374-1377. doi:10.1128/CVI.00378-08

[17] Federal Ministry of Health, “Abuja, Nigeria, National Guidelines for HIV and AIDS Treatment and Care in Adolescents and Adults,” pp. 1-67. http://www.who.int/hiv/pub/guidelines/nigeria_art.pdf

[18] T. de Siliva, C. van Tienen, S. Rowland-Jones and M. Cotton, "Dual infection with HIV-1 and HIV-2: Double Trouble or Destructive Interference?” HIV Therapy, Vol. 4, No. 3, 2010, pp. 305-323. doi:10.2217/hiv.10.26 